\title{
The plume of the Rhone: numerical simulation and remote sensing
}

\author{
CLAUDE ESTOURNEL, ${ }^{*}$ VERONIQUE KONDRACHOFF, ${ }^{*}$ \\ PATRICK MARSALEIX* and RAOUL VEHIL*
}

\begin{abstract}
The plume of the Rhone (western Mediterranean) is studied with the help of a three-dimensional ocean model using primitive equations. Particular attention is paid to the wind forcing. Three simulations of realistic cases, using wind and river discharge measurements, are described. Satellite observations of the plume make it possible to assess the quality of the numerical simulation in each case. The analysis of circulation enables an evaluation of the characteristic time scales of deformations in the plume during changes in wind conditions and also highlights the high sensitivity of the plume to the surrounding circulation, dominated by coastal currents associated with upwelling and downwelling motions induced by the northwest and southeast winds. (C) 1997 Elsevier Science Ltd
\end{abstract}

\section{INTRODUCTION}

The Rhone, the mouth of which is located in the Gulf of Lions (Fig. 1), is one of the main rivers to flow into the western Mediterranean. Over the past three years the river has experienced considerable changes in water level, causing serious floods in the region of the Camargue during the autumns of 1992,1993 and 1994. The mean discharge of the river is in general of the order of $1500 \mathrm{~m}^{3} \mathrm{~s}^{-1}$, and the increases in discharge observed in the spring and autumn of each year may easily attain $5000 \mathrm{~m}^{3} \mathrm{~s}^{-1}$. During these seasons the amount of particulate matter removed from the ground attains its maximum. The Rhone discharges up to 5 million tons of sediment per year (Courp and Monaco, 1990).

At the present time the coastal environment is the subject of concentrated worldwide interest, generated by the related economic and scientific stakes. Its study is all the more urgent given the threat of human activity. Indeed, the growth in river and coastal area industrialization and the excessive dumping of nutrients and pollutants into the sea are the factors destabilizing the coastal ecosystem. Ocean circulation in coastal areas and particularly in the vicinity of large estuaries, plays a crucial role in the dispersion of the particulate and dissolved matter in the ocean and may be studied by numerical modelling. The validation of models may be carried out either by means of in-situ measurements, in which case only isolated verifications may be performed, or by means of remote sensing

\footnotetext{
*Laboratoire d'Aérologie, UMR CNRS/UPS 5560 Université Paul Sabatier, Observatoire Midi-Pyrénées, 14 Avenue Edouard Belin, F-31400 Toulouse, France.
} 


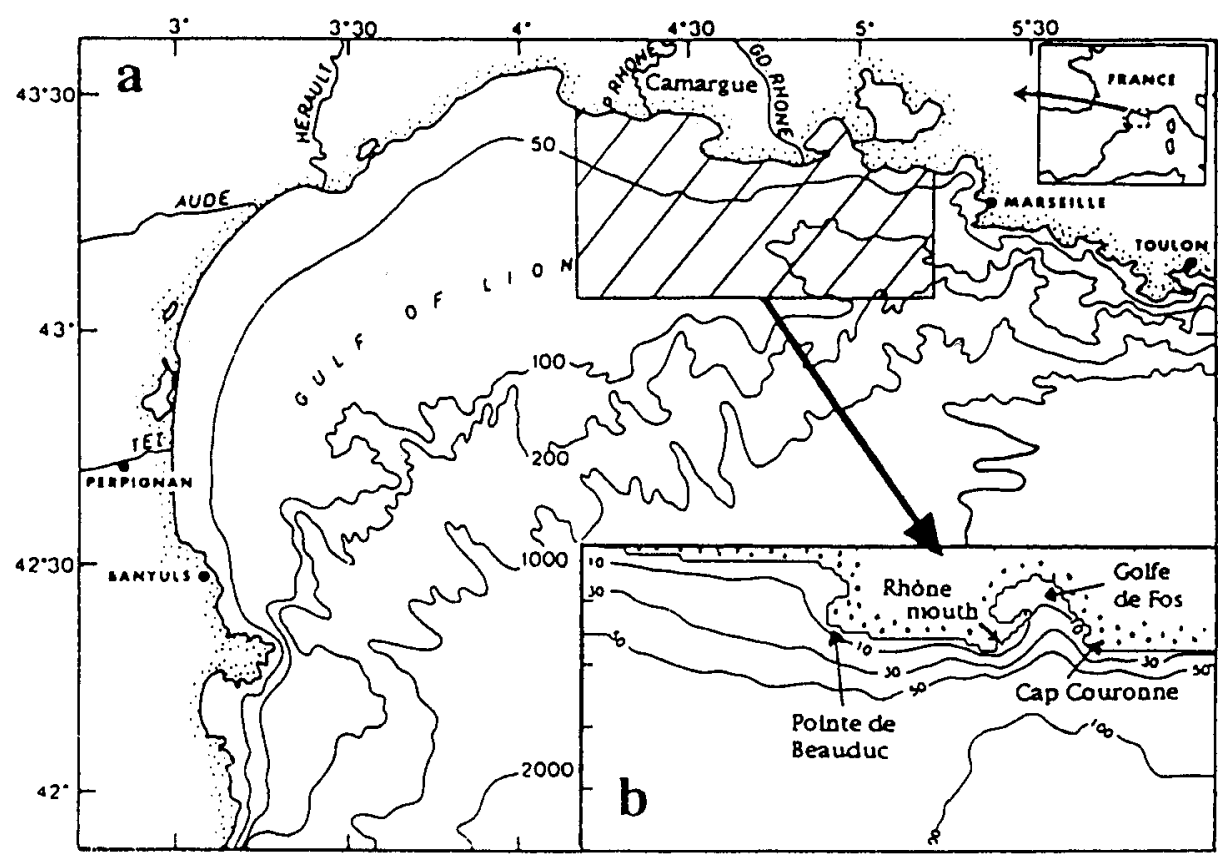

Fig. 1. (a) Map of the Gulf of Lions with locations referred to in the text. The model domain is hatched. (b) Coastline and depth contours in metres of the numerical model.

which supply synoptic observations. For the past few years surface temperature or sediment fields detected from space are used as current tracers (Balopoulos et al., 1986; Nihoul, 1984; Skibitzke, 1976). In this article a three-dimensional model is applied to the study of ocean circulation in the Rhone river dilution area and the realism of its solutions is assessed by comparison with satellite observations of the Rhone plume taken by the NOAA-11 AVHRR and expressed in visible wavelength seawater reflectances.

Various types of model have been developed for the study of freshwater plumes discharged by estuaries. Overall, we may cite three-dimensional primitive-equation models, which take into account the nonlinear dynamics, the time dependence and the processes of turbulent mixing. The weakness of these models lies in the fact that the solution of equations within a fixed horizontal grid does not enable an accurate representation of the frontal discontinuity bounding the plume. Undoubtedly, the most wellknown of these models is the one used by Chao and Boicourt (1986), Chao (1987) and Chao (1988). These articles deal with the internal structure of the plume, with its sensitivity to turbulence (bottom drag and vertical mixing), its response to forcing by a wind favouring the formation of coastal upwelling or downwelling, and the influence of the bottom slope of the estuary or continental shelf. The study by Weaver and Hsieh (1987) used a similar model to consider the influence of a submarine canyon in front of the estuary. It may be noted that the turbulence as considered in these models is a rough approximation, since the viscosities and diffusivities are assumed to be constant, thus leaving out of the picture the ranges of stability characterizing the plume and the adjacent and subjacent marine waters. A more refined approach was achieved by Oey and Mellor (1993), who made allowance for the turbulence by means of Mellor and Yamada's closure 
scheme of order 2.5 (Mellor and Yamada, 1982). Oey and Mellor's study focused on the unsteady dynamics of the plume, with the formation of meanders along the coastal current and the detachment of low-salinity pools. These characteristics seem linked to the fact that the turbulence was properly taken into account.

Another type of model considers the plume as a body of constant density, thin with respect to the total thickness of the water column and bounded by a frontal discontinuity. These models are particularly useful for the calculation of this frontal propagation, which is represented by a system of hyperbolic equations to be solved by the method of characteristics. Among the most well-known models of this type are the works by Garvine and O'Donnell (Garvine, 1987; O'Donnell, 1990) which progressively take into account more and more processes (the rotation of the Earth, time dependence, mixing, friction, ambient currents). This type of model, unlike the primitive-equation models discussed above, appears to be weaker with respect to the handling of the atmospheric forcings, turbulence, horizontal and vertical density gradients, and coastal circulation surrounding the plume. Finally, the primitive-equation models seem at the present time to be the most applicable to simulations of realistic cases.

When attempting to analyse the behaviour of the Rhone River plume when subjected to realistic and complex forcings, it is useful to examine first of all the main characteristics of the plume dynamics under the effect of simple forcings, as is clearly shown in the numerical simulations of Chao and Boicourt (1986) and Chao (1987). In the absence of wind forcing, when the river debouches into the sea, the circulation inside the plume is represented by an anticyclonic bulge as it exits the river mouth, which is prolonged by a coastal current to the right side of the mouth (as viewed in the seaward direction) in the northern hemisphere. The transition between the bulge and the coastal current is abrupt, since the surface current veers rapidly in a cyclonic manner. This transition is associated with downwelling motions. An undercurrent occurs beneath the plume which, depending on the bottom drag, may be present only under the bulge. The anticyclonic circulation in front of the mouth is associated with rising motions. The progression of the coastal current is characterized by the bore intrusion mechanism in which the rear advances faster then the nose. Several parameters may decrease the intrusion speed, such as the lessening of the density contrast between the freshwater and the ocean water, the increase in the vertical mixing, or else the bottom drag. In the presence of wind, the shape of the plume deviates to a greater or lesser extent from the description given above. The freshwater pool flows seaward while growing thinner when it is subjected to a parallel wind on the side favourable to upwelling. Water detachments may occur. The case of a wind generating coastal downwelling accelerates and deepens the coastal jet. The plume is also sensitive to tidal currents, as shown by Ruddick et al. (1995), who nevertheless concluded that the tidally-averaged salinity field of the Rhine plume is less strongly dependent on tidal amplitude than on the strength and direction of the wind.

As far as the Rhone River plume is concerned, Demarcq and Wald (1984) carried out a study using satellite observations from the AVHRR sensor in the infra-red thermal range. Their work made it possible to determine the responses of the Rhone River plume to wind and river discharge. Thus, the wind speed has little influence on the time taken by the plume to respond to the wind constraint, but plays a very important role in the increase of mixing. The river discharge is the parameter which controls the inertia of the plume with respect to wind effects. Forget et al. (1990), who have measured the radial currents in the 
Rhone River plume by means of a VHF radar, have shown that in many cases the frontal displacement responds quickly to wind forcing and in particular to changes in its direction.

This article briefly studies the hydrodynamic processes involved in the Rhone River plume, using the primitive-equation ocean model previously applied to the Gulf of Lions (Johns et al., 1992; Pinazo et al., 1996). Three situations, illustrated by satellite observations, characterized by a high variability in the wind (in both speed and direction) and in the Rhone River discharge, have been chosen for this study. A comparison will then be performed between the model output and the data as detected from space.

\section{OCEAN CIRCULATION IN THE GULF OF LIONS}

The Gulf of Lions constitutes the northwestern part of the Mediterranean Sea. Its shape corresponds approximately to a semi-circle with a $100 \mathrm{~km}$ radius. From Cape Creus to Marseilles, the continental slope (Fig. 1) is marked by a series of canyons which contrast with the monotony of the shelf topography. In this part of the Mediterranean Sea the general circulation is represented by the Liguro-Provençal-Catalan (LPC) current. This current runs alongside the Côte d'Azur and the Gulf of Lions following the continental shelf break to reach the Catalonian coast. On the continental shelf the associated currents are of the order of a few $\mathrm{cm} \mathrm{s}^{-1}$ (Millot, 1990) and are often negligible at the surface when compared to the circulation induced by the particularly strong winds in this region (Pinazo et al., 1996). In fact, Demarcq and Wald (1984) were unable to reveal an influence by the LPC current on the deviation of the plume. Two types of wind are predominant in this region. First of all, the north-west sector winds, induced by a ridge of high pressure over the near Atlantic, blow frequently (about every other day) and intensively throughout the year, encouraging the formation of coastal upwellings along the north coast. The most intense cold water upwellings occur along the rectilinear coasts (Millot and Wald, 1981), andin particular near the coasts of the Camargue, in front of which the Rhone River plume is most likely to flow. These gusts of wind encourage the formation of internal inertial waves (Millot and Crépon, 1981). Secondly, the east sector winds, representing an average of about $20 \%$ of the situations over the year, but more frequent in autumn and spring, during the passage of depressions across the Mediterranean encourage the formation of downwelling. The situations studied here are good representatives of these periods, with frequent alternations of northwest and southeast winds.

\section{PRESENTATION OF THE MODEL}

\subsection{Equations}

The model used is an adaptation of the one described by Johns et al. (1991). The governing equations are obtained by considering the conservation of mass, momentum, temperature and salinity, and by using the Boussinesq approximation and the hydrostatic equilibrium. Within a rectangular Cartesian coordinate system, $O x y z$, in which the origin, $O$, corresponds to the equilibrium level of the sea surface and $O z$ is directed upwards along the local vertical, the Reynolds-averaged components of the velocity, $u, v$ and $w$, satisfy

$$
\frac{\partial u}{\partial x}+\frac{\partial v}{\partial y}+\frac{\partial w}{\partial z}=0
$$




$$
\begin{aligned}
& \frac{\partial u}{\partial t}+\frac{\partial u u}{\partial x}+\frac{\partial v u}{\partial y}+\frac{\partial w u}{\partial z}-f v=-\frac{g}{\rho_{0}} \int_{z}^{\eta} \frac{\partial \rho}{\partial x} \mathrm{~d} z-g \frac{\partial \eta}{\partial x}+\frac{\partial}{\partial z}\left(K \frac{\partial u}{\partial z}\right)+A\left[\frac{\partial^{2} u}{\partial x^{2}}+\frac{\partial^{2} u}{\partial y^{2}}\right] \\
& \frac{\partial v}{\partial t}+\frac{\partial u v}{\partial x}+\frac{\partial v v}{\partial y}+\frac{\partial w v}{\partial z}+f u=-\frac{g}{\rho_{0}} \int_{z}^{\eta} \frac{\partial \rho}{\partial y} \mathrm{~d} z-g \frac{\partial \eta}{\partial y}+\frac{\partial}{\partial z}\left(K \frac{\partial v}{\partial z}\right)+A\left[\frac{\partial^{2} v}{\partial x^{2}}+\frac{\partial^{2} v}{\partial y^{2}}\right]
\end{aligned}
$$

where $f$ denotes the Coriolis parameter, $\eta$ the position of the sea-surface, $A$ the horizontal diffusion coefficient and $\rho_{0}$ a reference density. The displacement of the sea surface is deduced from a vertically integrated form of the equation of continuity (1) in which

$$
\frac{\partial \eta}{\partial t}+\frac{\partial}{\partial x}(H \bar{u})+\frac{\partial}{\partial y}(H \bar{v})=0
$$

where $H$ denotes the total depth and the overbar a depth average. In order to avoid the computation load that the solution of the full set of three-dimensional equations characterizing the fast moving surface wave would entail, a mode-splitting approach is used to calculate $u, v$ and $\eta$ separately from the three-dimensional structure. This is achieved by solving a set of depth-integrated equations, including equation (4), in which

$$
\begin{gathered}
\frac{\partial H \bar{u}}{\partial t}+\frac{\partial H \bar{u} \bar{u}}{\partial x}+\frac{\partial H \bar{v} \bar{u}}{\partial y}+H f \bar{v}+\boldsymbol{g} H \frac{\partial \eta}{\partial x}=\Pi_{x} \\
\frac{\partial H \bar{v}}{\partial t}+\frac{\partial H \bar{u} \bar{v}}{\partial x}+\frac{\partial H \bar{v} \bar{v}}{\partial y}-H f \bar{u}+\boldsymbol{g} H \frac{\partial \eta}{\partial y}=\Pi_{y} .
\end{gathered}
$$

The right-hand sides of equations (5) and (6), which correspond to the depth integration of the $z$-dependent terms of equations (2) and (3), are calculated according to Blumberg and Mellor (1987) and the details are not reproduced here.

The density, $\rho$, may be derived from the water salinity and temperature, $S$ and $T$, using the following linearized equation of state:

$$
\rho=\rho_{0}\left(1-\alpha\left(T-T_{0}\right)+\beta\left(S-S_{0}\right)\right)
$$

where the thermal expansion coefficient, $\alpha$, and the saline contraction, $\beta$, are respectively taken to be $2.4110^{-4} \mathrm{~K}^{-1}$ and $7.4510^{-4} \mathrm{psu}^{-1} . T_{0}$ and $S_{0}$ are respectively the reference temperature and salinity corresponding to $\rho_{0}$. The temperature and salinity are determined from:

$$
\frac{\partial(T, S)}{\partial t}+\frac{\partial u(T, S)}{\partial x}+\frac{\partial v(T, S)}{\partial y}+\frac{\partial w(T, S)}{\partial z}=\frac{\partial}{\partial z}\left(K \frac{\partial(T, S)}{\partial z}\right)+A\left[\frac{\partial^{2}(T, S)}{\partial x^{2}}+\frac{\partial^{2}(T, S)}{\partial y^{2}}\right] \text {. }
$$

The transfer coefficient $K$ is defined in terms of turbulence energy density, $E$, using the following relation:

$$
K=c_{k} l_{k} E^{1 / 2}
$$

$E$ is determined from:

$$
\frac{\partial E}{\partial t}+\frac{\partial u E}{\partial x}+\frac{\partial v E}{\partial y}+\frac{\partial w E}{\partial z}=K\left[\left(\frac{\partial u}{\partial z}\right)^{2}+\left(\frac{\partial v}{\partial z}\right)^{2}\right]+\frac{g}{\rho_{0}} K \frac{\partial \rho}{\partial z}+\frac{\partial}{\partial z}\left(K \frac{\partial E}{\partial z}\right)-\varepsilon .
$$

The rate of loss of the turbulence energy, $\varepsilon$, is represented according to 


$$
\varepsilon=\frac{c_{\varepsilon} E^{3 / 2}}{l_{\varepsilon}}
$$

Following Caniaux et al. (1993), the turbulent scales $l_{\varepsilon}$ and $l_{k}$ are functions of two length scales, $l_{u}$ and $l_{d}$, which represent upward and downward conversions of turbulence energy into potential energy (Bougeault and Lacarrère, 1989):

$$
\begin{gathered}
l_{k}=\min .\left(l_{u}, l_{d}\right), \quad l_{\varepsilon}=\left(l_{u} \times l_{d}\right)^{1 / 2}, \\
\frac{g}{\rho_{0}} \int_{z}^{z+l_{u}}\left(\rho(z)-\rho\left(z^{\prime}\right)\right) \mathrm{d} z^{\prime}=E(z), \\
\frac{g}{\rho_{0}} \int_{z}^{z-l_{d}}\left(\rho(z)-\rho\left(z^{\prime}\right)\right) \mathrm{d} z^{\prime}=E(z) .
\end{gathered}
$$

The empirical constants, $c_{k}$ and $c_{\varepsilon}$, calibrated for the turbulence closure scheme, equations (10)-(12), by Gaspar et al. (1990), are taken to be 0.1 and 0.7 , respectively. The numerical study by Ruddick et al. (1995) should be mentioned here, as it tested the sensitivity of the freshwater plume dynamics to various turbulence schemes, including among others the higher order closures of Mellor and Yamada (1982). Ruddick et al. concluded that the best compromise between quality of results and computation load lies in the use of a prognostic kinetic energy equation of type (10) and of a simple formulation of the mixing lengths.

As will be discussed at the end of this section, the shape of the plume is identified by the concentration of suspended particles, $C$, discharged by the Rhone River into the Gulf of Lions, as calculated from the following equation:

$$
\frac{\partial C}{\partial t}+\frac{\partial u C}{\partial x}+\frac{\partial v C}{\partial y}+\frac{\partial\left(w-w_{s}\right) C}{\partial z}=\frac{\partial}{\partial z}\left(K \frac{\partial C}{\partial z}\right)
$$

where $w_{s}$, the settling velocity, will be discussed later. The horizontal diffusion, used in equations (2), (3) and (8) for the sole purpose of stabilizing the model, was not included for the particles in order to preserve the horizontal gradients inside the plume as much as possible.

\subsection{Boundary conditions}

The boundary conditions at the free surface and at the sea floor are:

$$
\begin{aligned}
& \rho_{0} K\left(\frac{\partial u}{\partial z}, \frac{\partial v}{\partial z}\right)=\left\{\begin{array}{lll}
\left(\tau_{s x}, \tau_{s y}\right) & \text { at } & z=\eta \\
\left(\tau_{b x}, \tau_{b y}\right) & \text { at } & z=-h
\end{array}\right. \\
& E=\left\{\begin{array}{lll}
\frac{\tau_{s}}{\rho_{0} \sqrt{c_{\varepsilon} c_{k}}} & \text { at } & z=\eta \\
\frac{\tau_{b}}{\rho_{0} \sqrt{c_{\varepsilon} c_{k}}} & \text { at } & z=-h
\end{array}\right. \\
& \rho_{0} K\left(\frac{\partial T}{\partial z}, \frac{\partial S}{\partial z}\right)=0 \quad \text { at } \quad z=\eta \quad \text { and at } \quad z=-h
\end{aligned}
$$


where $\tau_{s}$ is the wind stress $(\mathrm{Wu}, 1980)$, and $\tau_{b}$, the bottom stress (Blumberg and Mellor, 1987).

A no-flux condition is applied across closed lateral boundaries. Radiation conditions are applied at the open lateral boundaries.

The liquid and solid discharges of the Rhone into the sea debouch from a channel in which the model equations are reduced to a two-dimensional system, $O x z$, where $O x$ corresponds to the river axis. This system consists of simply eliminating the transverse components of the current and the gradients which are perpendicular to the river axis in equations (1)-(16). The width of the Rhone River mouth is fixed at $1 \mathrm{~km}$, which closely approximates reality. As the horizontal resolution of the three-dimensional ocean model is also $1 \mathrm{~km}$, the coupling with the river model is simply:

$$
\phi_{\text {river }}=\phi_{\text {ocean }}
$$

where $\phi$ represents any variable in equations (1)-(16).

\subsection{The model grid}

Equations are solved on a three-dimensional 'staggered' $\mathrm{C}$ grid (Arakawa and Suarez, 1983). The horizontal resolution is $1 \mathrm{~km} \times 1 \mathrm{~km}$. A 10-level sigma coordinate system following the topography is used to represent the irregular coastal bathymetry. A leap-frog differencing scheme associated with an Asselin (1972) filter is used for the time stepping. The internal and external time steps are respectively $180 \mathrm{~s}$ and $7 \mathrm{~s}$. The advection scheme is upstream, which is suitable for the advection of frontal structures (Haltiner and Williams, 1980). In some cases, the introduction of horizontal diffusion was necessary to eliminate numerical instabilities. For the sake of homogeneity the value of the horizontal diffusion coefficient was fixed at $10 \mathrm{~m}^{2} \mathrm{~s}^{-1}$ in all simulations. When the first case studied on this article (11 September 1993) was compared with a simulation using a value of $5 \mathrm{~m}^{2} \mathrm{~s}^{-1}$, only slight differences were found.

\subsection{Initialization and forcing}

For each situation, the simulations begin at 0000 UTC, 3 days before the date of the satellite observation. This duration was chosen as a function of the time scales which characterize the response of the coastal ocean to a variable atmospheric forcing (succession of upwelling and downwelling) and of the particle residence time in the surface plume as it is seen from outer space. Since the characteristic size of the plume on the satellite image is $40 \mathrm{~km}$ and the mean velocities of front advancement as determined by the model are $0.2 \mathrm{~m} \mathrm{~s}^{-1}$, the resultant characteristic time is between 2 and 3 days. On the other hand, the simulations cannot exceed this duration by much, due to the simplifications introduced: (i) the omission of the surface forcing of the temperature and salinity by the radiative and heat flux, and by the evaporation/precipitation flux, which could restratify the surface waters which are subjected, as will be seen later, to particularly strong winds; (ii) the zero gradients at the open boundaries; and (iii) the choice of a particle settling velocity to which the plume size is sensitive.

For each of the three situations, the wind used in the model is taken from smoothed 
(a)

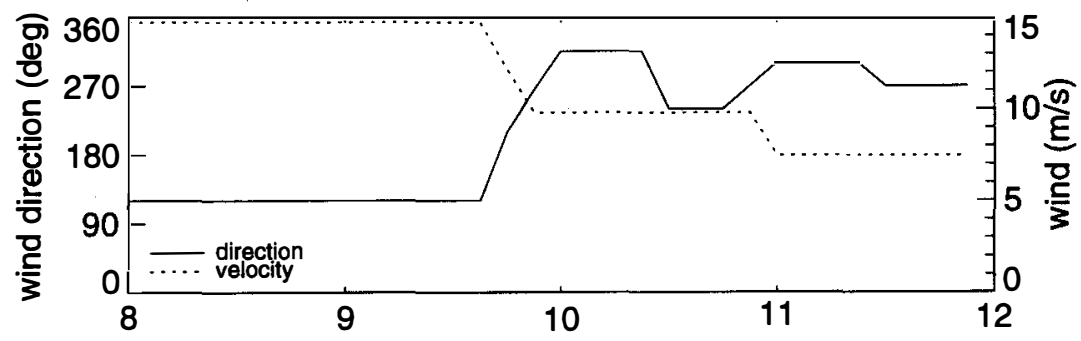

(b)

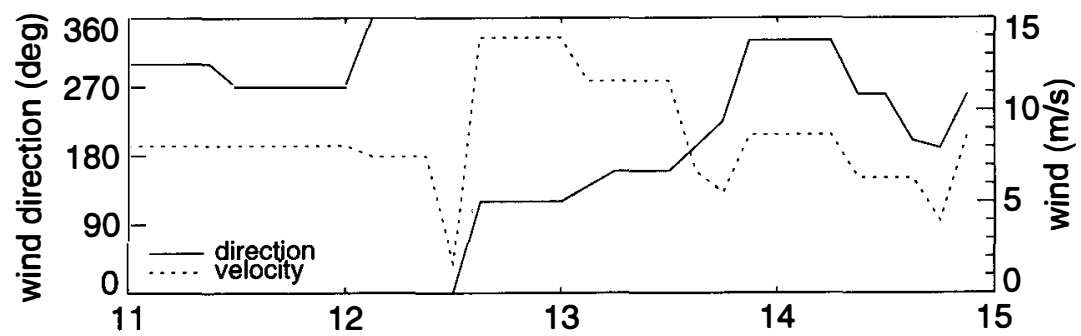

(c)

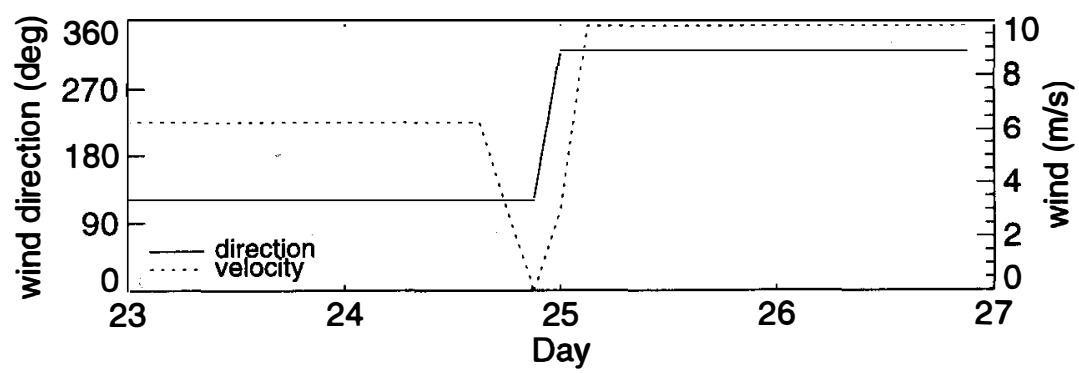

Fig. 2. Wind velocities and directions used in the simulations of the three considered periods of September 1993.

measurements of the Cap Couronne meteorological station. These were corrected in order to make allowance for differences between the sea and land according to Hsu's relation (Hsu, 1986), which stems from a statistical study performed using pairs of wind measurements, taken above the land and above the sea, under different meteorological conditions:

$$
\text { Usea }=1.17 \text { Uland }+1.62 .
$$

Figure 2 shows the wind as corrected above for the three simulations.

At initialization, the temperature and salinity fields are horizontally homogeneous. The temperature and salinity profiles (Fig. 3) are taken respectively from measurements obtained in mid-September by Millot (1976) and measurements obtained during the ECOR I campaign at the end of the summer of 1986 in the canyon of the Grand Rhone (Durrieu de Madron et al., 1990). These two profiles are characterized by a $20-\mathrm{m}$ thick mixed layer.

Upon entry into the channel, the liquid discharge is set according to measurements taken at the Beaucaire station (Fig. 4) located upstream from the Grand Rhone/Petit 


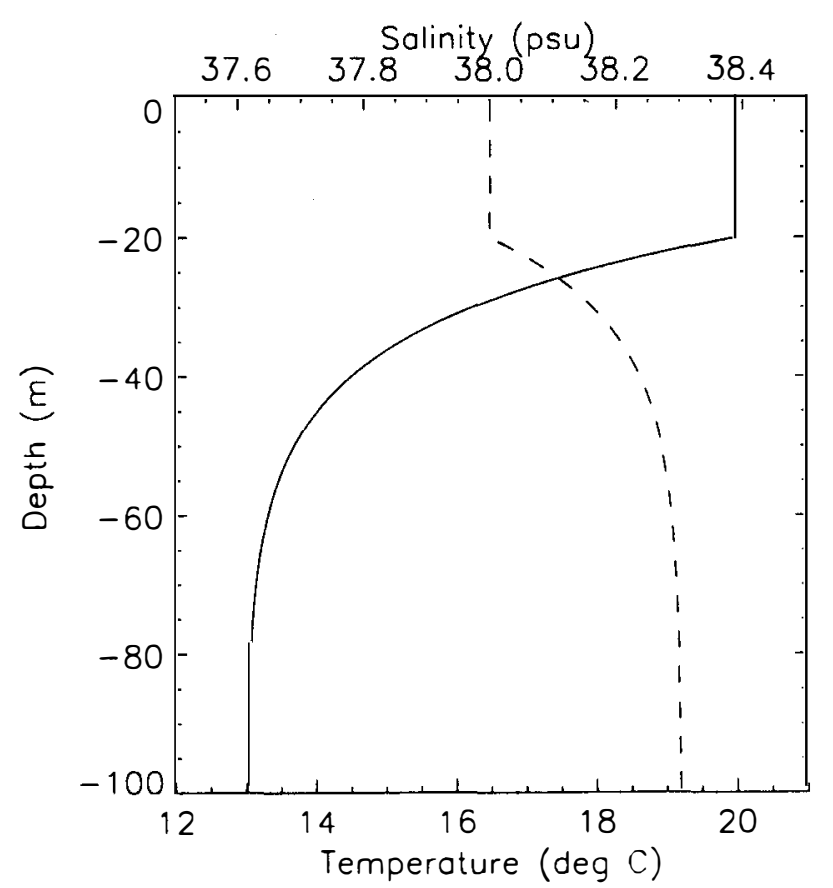

Fig. 3. Initial vertical distributions of temperature (solid line) and salinity (dashed line).

Rhone separation. The discharge of the Petit Rhone, which represents about $10 \%$ of that of the Grand Rhone, is consequently subtracted from the Beaucaire measurement. The solid discharge is given in arbitrary units. The particle concentration at the channel source is constant for the length of the simulation.

The settling velocity of suspended matter depends on several parameters, which vary over space and time. Among others, the granulometry of the particles carried by the river

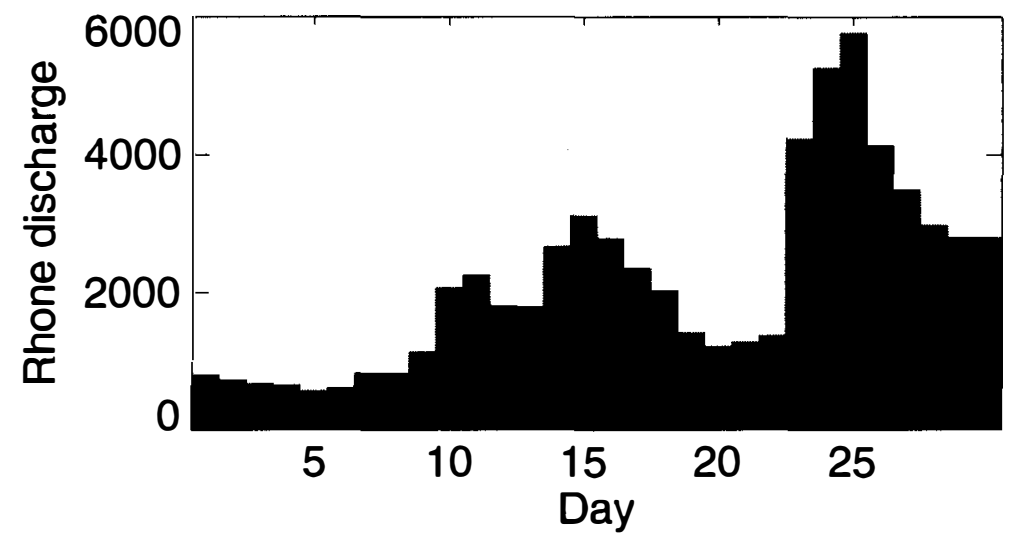

Fig. 4. Discharge of the Rhone River (in $\mathrm{m}^{3} \mathrm{~s}^{-1}$ ) measured in September 1993 by the Compagnie Nationale du Rhone at Beaucaire. 
can change in flood periods, since this is the period when the largest particles are transported, and it is also sensitive to the flocculation processes, themselves strongly dependent on the salinity. It is difficult to integrate this variability into the model, as this would entail the inclusion of the various types of particles as well as the physical mechanisms they undergo along their trajectory. Moreover, since the goal here is not to quantify the suspended matter in the plume but to use a tracer whose spatial distribution is directly comparable to the satellite observation of the plume, we thus fixed the settling velocity as constant over space and time. The value chosen, $4.710^{-5} \mathrm{~m} \mathrm{~s}^{-1}$, is suggested by Brun-Cottan and Li (1991), and corresponds to the Stokes Law applied to a $20 \mu \mathrm{m}$ diameter, which is the mean size of Rhone River particles as measured $3 \mathrm{~km}$ in front of the river mouth. This velocity is comparable, and often even less than, the vertical velocities characterizing the ocean flow near the coast (coastal upwelling and downwelling and, especially, vertical movements inside the plume). Consequently, the spatial distribution of the particles after 3 days of simulation varies very little from the one obtained with lower settling velocities. In the case of longer simulations on the other hand, the extension of the plume is more sensitive to the settling velocity, thus requiring this velocity to be increased if the model results are to be comparable to the satellite images. The aim of such an increase would be to make allowance for those processes which have not been taken into account in the model, such as flocculation and aggregation, in particular as concerns biogenic particles, which are present in high concentrations in river plumes.

\section{RESULTS}

We examined the Rhone River flood period of September 1993. During this highly perturbed period, both from a meteorological and a hydrological point of view, the satellite data often retraced unstable situations, which are difficult to fully interpret by merely examining the images. Moreover, due to poor weather conditions we were unable to benefit from the chronological follow-up provided by the NOAA Series of satellite images. Numerical modelling in this case is thus an essential tool for the analysis of a real situation and for understanding the mechanisms which generated it. The comparison with the satellite image supplies a final validation, enabling an assessment of the model accuracy. This comparison is carried out using the seawater reflectances in channel 1 of the AVHRR, characterizing the turbidity of water in which suspended matter content is a predominant factor. The satellite signal processing, which is described in Kondrachoff $e t$ al., 1994 will not be detailed here. It should be noted that the modification of the signal by atmospheric effects has been calculated with the 5S code (Tanré et al., 1986), with the exception of the aerosol and foam reflectances which have been eliminated by Stumpf's method (Stumpf, 1987) using a combination of channels 1 and 2 . The images presented below are projected around a pole of latitude $\Phi=43.483^{\circ} \mathrm{N}$ and longitude $l=4.1275^{\circ} \mathrm{E}$, on a grid with coordinates expressed in distance - the elementary mesh represents $500 \mathrm{~m} \times$ $500 \mathrm{~m}$. The size of the represented area is $50 \mathrm{~km}$ from north to south by $90 \mathrm{~km}$ from east to west. It corresponds to the coverage area of the hydrodynamic model (Fig. 1). The numerical studies concerning the 11, 14 and 26 September 1993 will now be discussed.

\subsection{The situation on 11 September 1993}

4.1.1. Examination of the satellite image. The AVHRR reflectances calculated from the image of 15.30 hours are shown in Fig. 5(a). The plume extends along an axis which is almost west/east and the concentrations of matter are higher in the eastern part than in the 
a
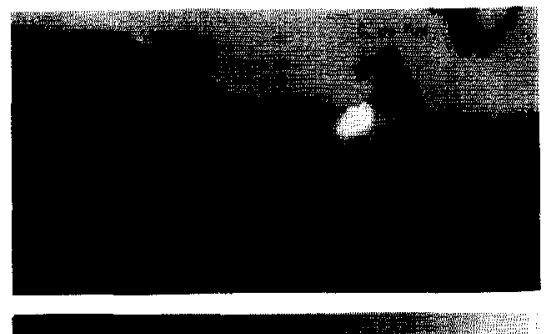

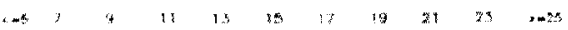

C
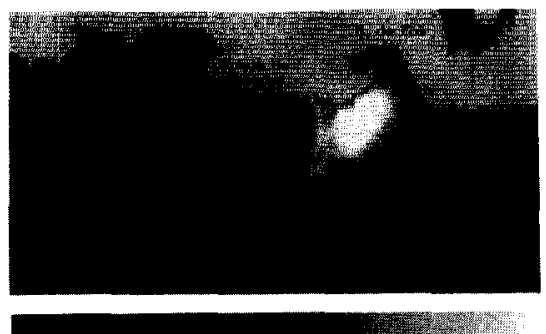

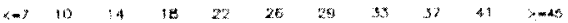

e
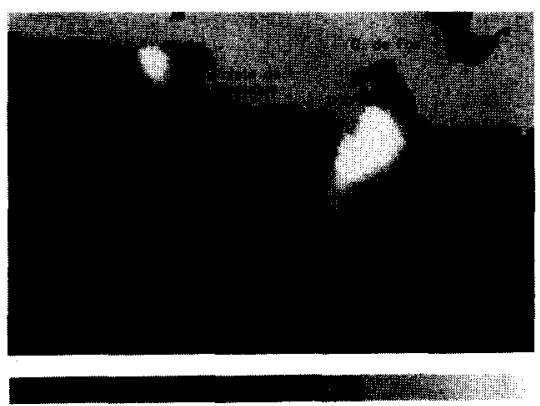

$\therefore \quad \begin{array}{llllllllll}11 & 15 & 19 & 24 & 28 & 37 & 37 & 41 & 45 & \times-50\end{array}$
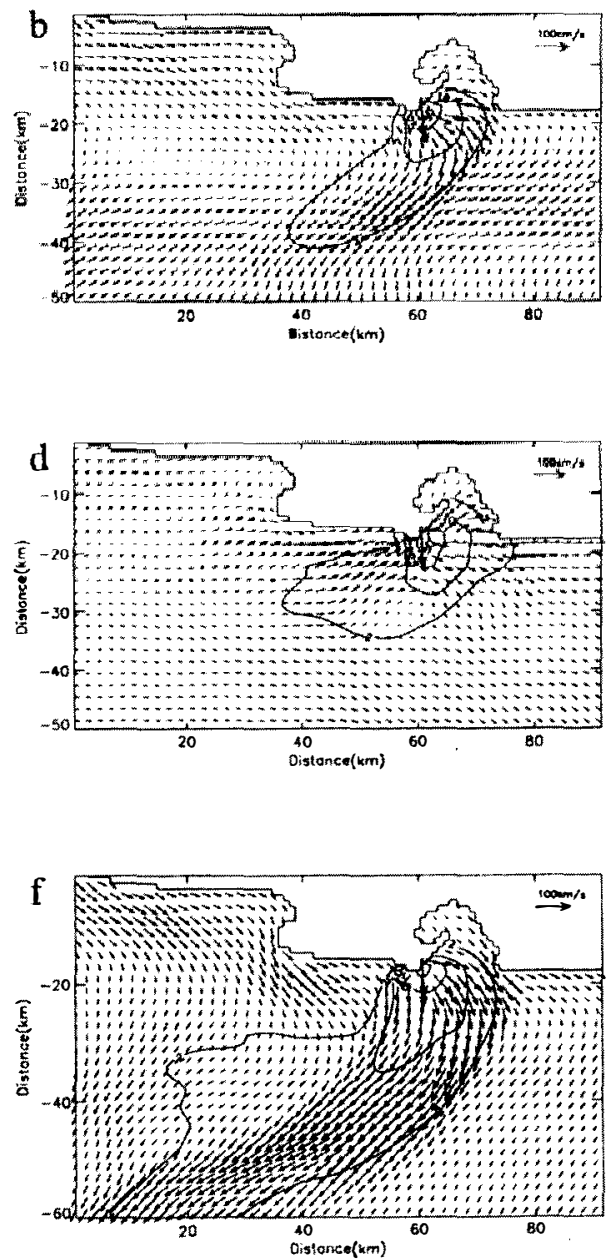

Fig. 5. Comparison between satellite observations (left panel) expressed in water reflectances (in tenths of percent) and numerical experiments (right panel) expressed in particles concentration (in arbitrary units referring to a concentration of 100 in the river). Contours: 2,10,25,50. Computed surface currents are also represented. (a) and (b) 11 September 1993; (c) and (d) 14 September 1993; (e) and (f) 26 September 1993. 
western part, which appears more diffuse at its edge, suggesting that the waters here have spent more time in the ocean. To the west of the Point of Beauduc, the turbid pool associated with the Petit Rhone is visible. It should be noted that the discharge of the Petit Rhone is not included in these numerical simulations.

4.1.2. Meteorological and hydrological conditions. The river discharge was approximately $2300 \mathrm{~m}^{3} \mathrm{~s}^{-1}$ on 11 September. This was the first flood after the summer, during which the mean discharge had been less than $1000 \mathrm{~m}^{3} \mathrm{~s}^{-1}$. The meteorological data show that a strong southeast wind was globally present until 10 September, with a mean speed of $15 \mathrm{~m}$ $\mathrm{s}^{-1}$. The wind then reversed direction to a northwest wind and its speed decreased to $10 \mathrm{~m}$ $\mathrm{s}^{-1}$. The wind then remained overall in the western sector, with lower velocities on 11 September.

4.1.3. Comparison of the satellite image with the model results. The simulation results [Fig. 5(b)] and the satellite observation [Fig. 5(a)] both display an elongated plume shape. The plume contains an area of high particle concentration near the mouth and an area of lower concentration to the west, the tip of which veers towards the south. This characteristic is clearly visible on the satellite image, but may also be discerned in the surface circulation of the model, which veers towards the south at the southern part of the modelled region. The main inaccuracy of the model resides in the fact that the north/south component of the plume's orientation is too prominent.

4.1.4. The simulation of 11 September 1993. During the first two days of simulation, the southeast wind induced an Ekman transport globally directed shoreward. This resulted in a coastal downwelling situation characterized by a water accumulation at the coast, accompanied by a geostrophic current directed westward which limited the eastward expansion of the plume [Fig. 6(a)]. At the coast, the downwelling forced the light surface waters down, thus causing a north-south density gradient in depth. When the wind changed direction to the northwest, it tended, under the effect of the Ekman drift, to depress the surface. However, the adjustment to the previously generated north-south density gradient, which has only just begun to be reversed at the coast by the present upwelling conditions, has resulted in the continuance of a pronounced south-north surface elevation gradient farther seaward, which explains the persistence of a strong westward current a few kilometers from the coast in the eastern part of the area under consideration two days after the wind reversal [Fig. 5(b)]. In the western part, on the other hand, the coastal current had been reversed and the situation at hand was thus a classical upwelling situation with a western coastal current. The contrast with the eastern part could be explained by a difference in downwelling-generated stratification over areas with very different depths - unlike the east, where the bathymetrical slope is steep, the western region is characterized by a widening of the continental shelf and thus shallower depths. The mixed layer induced by the downwelling movements occupied the entire water column up to $15 \mathrm{~km}$ from the coast, within which range the horizontal density gradient was very slight. Consequently, in this area the reversal of the wind direction was accompanied rapidly by an inversion of the surface elevation gradient (Fig. 7). Farther out to sea, about $20 \mathrm{~km}$ away from the coast, when the water column became thicker than the surface mixed layer, the downwelling signature could be observed on the density and surface elevation gradients as had been manifested in the eastern part, forcing a westward oriented 
current. The behaviour of the plume will now be considered with regards to the different successive wind directions and the considerable coastal current speeds. The vertical structure of the salinity in the plume during the period of the southeast wind is shown in a west-east section [Fig. 8(a)] taken $3 \mathrm{~km}$ to the south of the river mouth. As was the case in Fig. 6(a), isohalines compressed by the westward oriented coastal current could be observed to the east of the river mouth. On the other side, the freshwaters occupied a layer which thickened markedly towards the west and mixed over about $25 \mathrm{~m}$. The north-south salinity section, $11 \mathrm{~km}$ to the west of the river mouth, [Fig. 8(b)] also indicates a considerable mixing action induced by the descending motions linked to the deviation of the surface current against the coast under the effect of the Coriolis force and the wind.

Figure 6(b) shows the salinity and the surface circulation on 10 September at 02.00 hours. The wind had been stable in the northwest direction for the past 2 hours, after a transition through the southwest which lasted 9 hours [Fig. 2(a)]. To the west of the river mouth, the current had already reversed near the coast. In the open sea, the circulation was dominated by inertial oscillations in the form of a clockwise current rotation which continued until the end of the simulation. The amplitude of these oscillations increased with the weakening of the wind which had accompanied its rotation a few hours earlier. Near the coast the circulation induced by the wind tended to pull the plume away from the coast. However, low-salinity waters were still to be found alongshore. These were the freshwaters of the former plume, downwelled by the southeast wind and then upwelled by the northwest wind. The rise of the isohalines to the coast may be seen by comparing Figs 9 and $8(b)$. The plume rematerialized at the river mouth, where the newly discharged waters
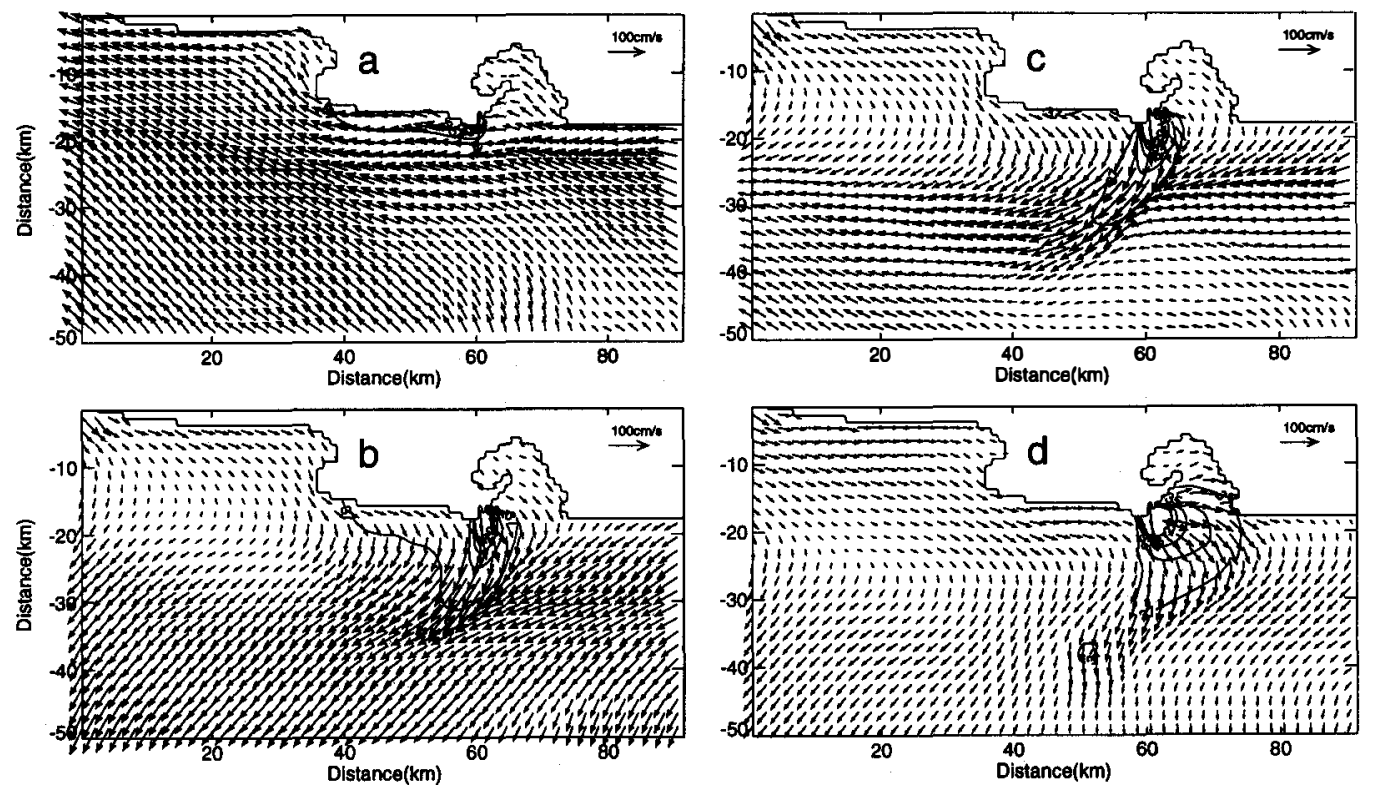

Fig. 6. Computed surface salinities and currents corresponding to different times: (a) 9 September 1993,15.00 hours, (b) 10 September 1993, 02.00 hours, (c) 10 September 1993, 09.00 hours, (d) 10 September 1993, 21.00 hours. Interval between salinity isocontours: 2 psu, contours lower than 29 psu are not plotted for clarity. 


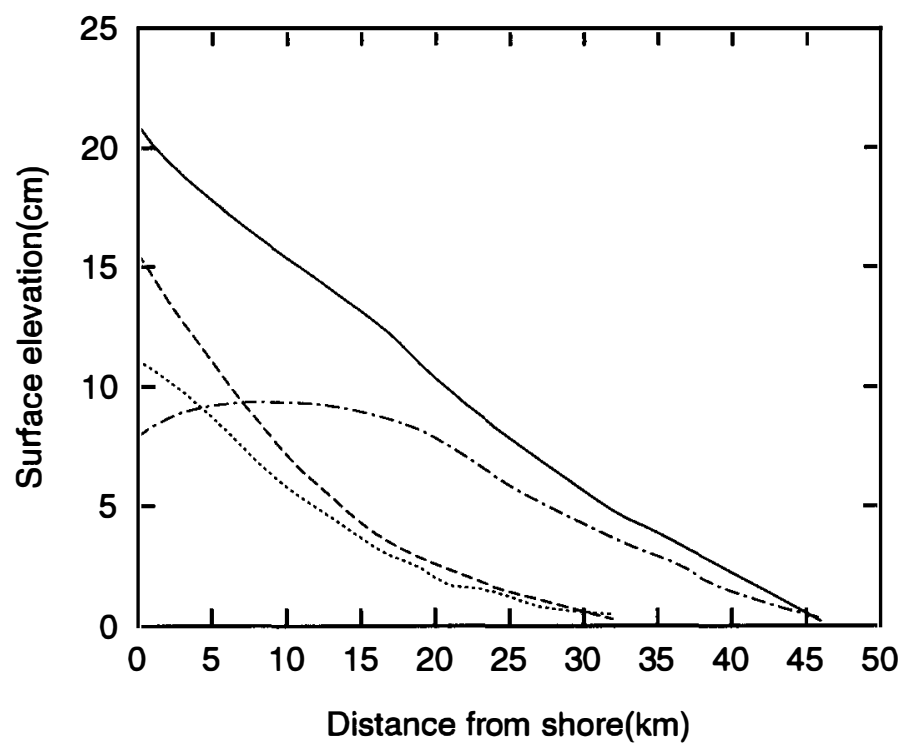

Fig. 7. North-south sections of surface elevation computed in the western $(40 \mathrm{~km}$ westward of the Rhone mouth) and eastern ( $22 \mathrm{~km}$ eastward of the Rhone mouth) parts of the domain during the southeasterly wind (9 September 1993, 15.00 hours) and after the backing of the wind (10 September 1993, 02.00 hours). Solid line: western section, 9 September 1993, 15.00 hours; dashed dotted line: western section, 10 September 1993, 02.00 hours; dashed line: eastern section,

9 September 1993, 15.00 hours; dotted line: eastern section 10 September 1993, 02.00 hours.

were then directed towards the south. The river mouth is located in a current collision area, which generated a high-convergence area on the eastern bound of the plume, making the plume narrower. The situation on 26 September, in which the collision did not occur, shows that the northwest wind is in this case much more favourable to an eastward expansion of the plume. At 09.00 hours [Fig. 6(c)], the plume detached itself completely from the coast and its direction matched satellite observations during northwest winds, as reported by Demarcq and Wald (1984) (see Section 5). The low gradient area found between the 35 and 37 psu isohalines indicated once again rotation of the plume. The former plume was still visible alongshore to the west, while to the east a pronounced salinity front, deflected by the eastern circulation, could be observed. In fact, the active part of the plume would require about 6 hours after stabilization of the northwest wind before stabilizing itself. This order of magnitude is compatible with the observations of Demarcq and Wald (1984). The complete rotation of the plume from the position induced by the southeast wind until total detachment from the coast lasted almost 18 hours. On 10 September at 21.00 hours, the wind direction was west after a 9-hour period during which it had tended to southwest. This wind sector directed the river water into the Gulf of Fos [Fig. 6(d)], a fact which is encouraged by the recent reversal of the coastal current due to the persistent upwelling conditions. Little more change occurred in the meteorological conditions until the next day at the time of the image acquisition, apart from the fact that the wind continued to weaken. The plume maintained its direction [Fig. 5(b)] but its surface area increased, developing towards the southwest in parallel to the doubling of the river discharge, as measured by the Beaucaire station between the 9 and 10 September. 

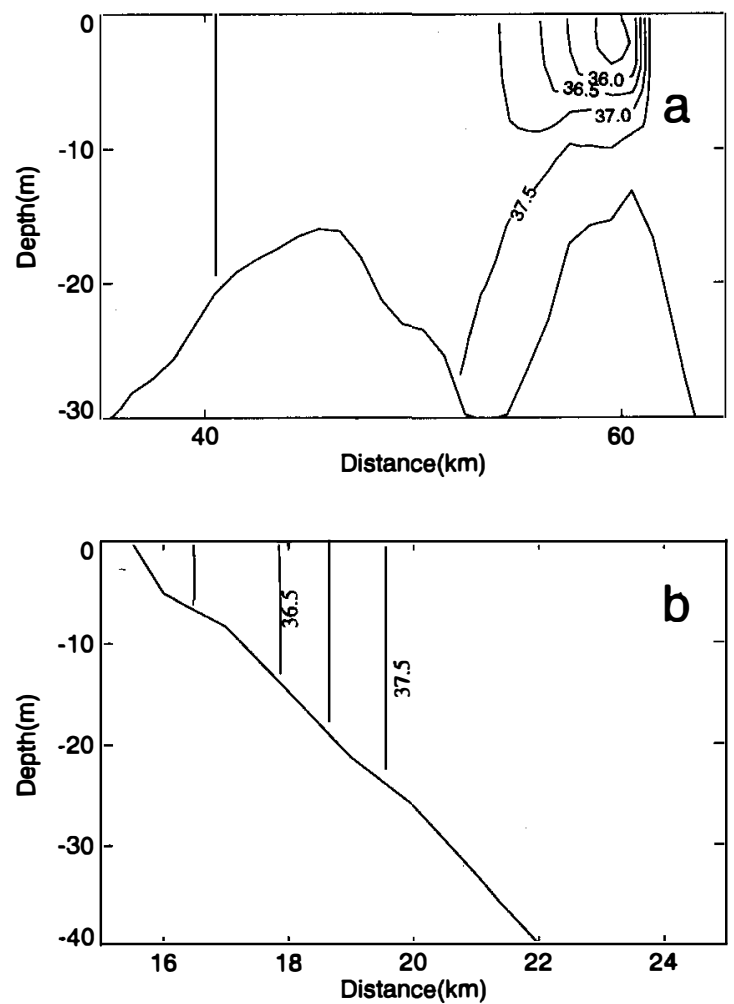

Fig. 8. Vertical sections of salinity corresponding to 9 September 1993 at 15.00 hours during the southeasterly wind, (a) west-east section taken $2 \mathrm{~km}$ southward of the river mouth; (b) northsouth section taken $12 \mathrm{~km}$ westward of the river mouth.

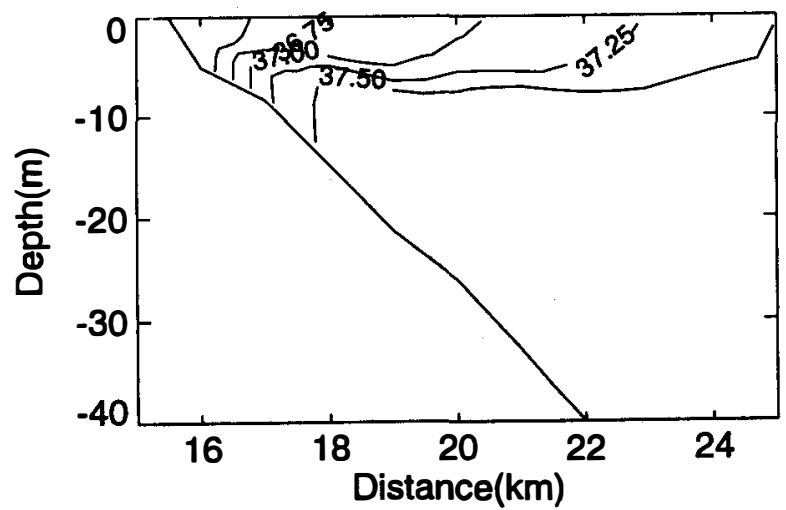

Fig. 9. North-south vertical section of salinity taken $12 \mathrm{~km}$ westward of the river mouth after the backing of the wind (10 September 1993 at 02.00 hours). 

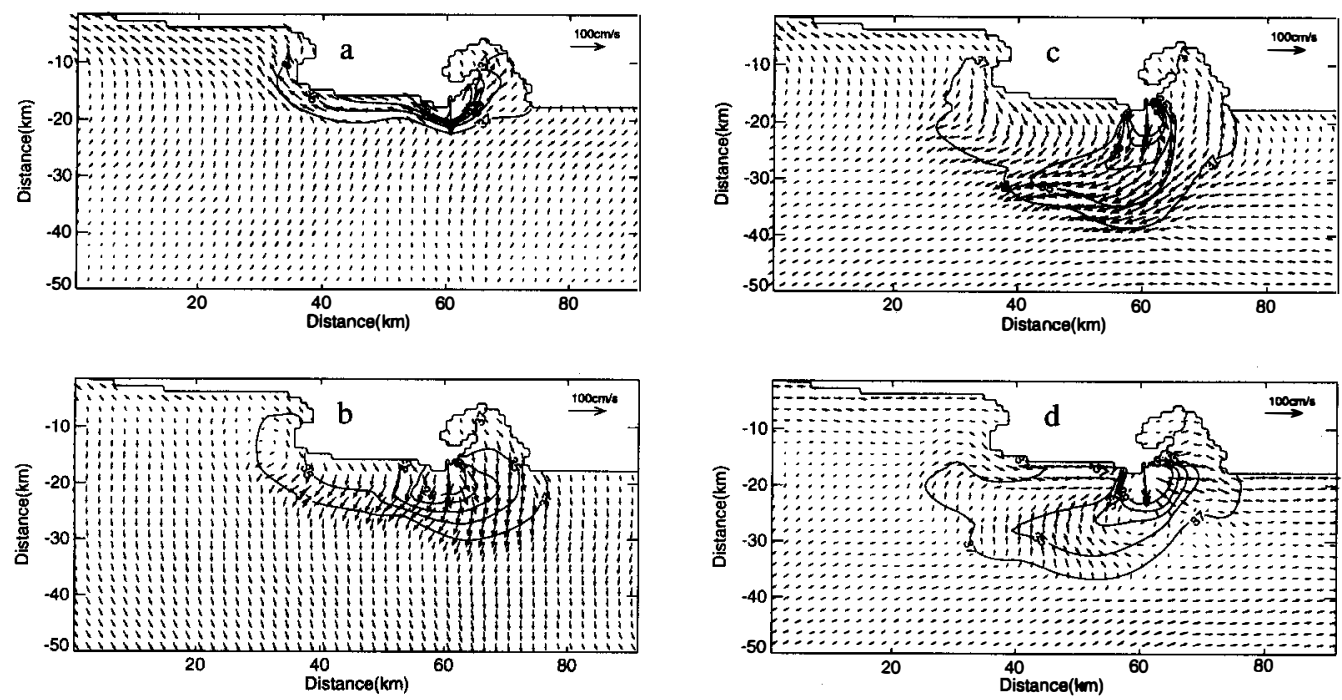

Fig. 10. Computed surface salinities and currents corresponding to different times: (a) 13 September 1993, 12.00 hours, (b) 13 September 1993, 22.30 hours, (c) 14 September 1993, 06.00 hours, (d) 14 September 1993, 12.00 hours. Interval between salinity isocontours: 2 psu, contours lower than 29 psu are not plotted for clarity.

sediment particles. This fact, when combined with the existence of ascending vertical velocities in front of the river mouth (Chao and Boicourt, 1986), the order of magnitude of which is greater than that of the particle settling velocity, could help explain the fact that the reflectance maximum observed by the satellite is detached from the river mouth.

4.2.4. The simulation of 14 September 1993. The meteorological conditions were opposite to those of the previous simulation, since during the first 36 hours of simulation, the wind was in the sector varying between north and west, favouring the formation of coastal upwelling, and then turned into a southeast wind. As in the previous situation, the response time of the coastal circulation to the change in wind direction was more rapid in the shallower western part of the area under consideration than in the eastern part [Fig. $10(a)$ ]. Indeed, to the west of the river mouth the westwards coastal current, characteristic of a downwelling situation, had been well-established after 24 hours of forcing, unlike the eastern area where the isopycnals which had been strongly upwelled for the past 36 hours had only just begun to tilt downwards at the coast. One effect on the plume was the penetration of river water into the Gulf of Fos, which had not been possible in the previous simulation [Fig. 6(a)] due to the existence of an eastern coastal circulation. It should, however, be noted that in the current situation other parameters are more favourable to the penetration of the plume into the Gulf of Fos than in the case of 9 September, in particular the south-southeast sector of the wind (east-southeast on the 9September), the lower speed of the wind and the higher discharge of the Rhone. Demarcq and Wald (1984) have also observed that a global southeastern atmospheric forcing will in certain cases result in a penetration into the Gulf of Fos [see Fig. 14(b)].

Starting at 15.00 hours on 13 September 1993, the wind changed direction to a southwest and then a west wind, and at 21.00 hours it stabilized at the northwest. At 22.30 hours it 
could be seen that the wind effect was to force a seaward expansion of the newly discharged freshwaters and to push the low-salinity waters, which had previously been accumulated at the coast, offshore [Fig. 10(b)], thus bringing to mind the southeast-northwest wind rotation in the 11 September simulation. The low-salinity waters were still present alongshore to the west of the river mouth and in the Gulf of Fos, corresponding to the upwelled waters, which explains why the plume did not yet appear to have detached itself from the coast. The southern fringe of the former plume was characterized by strong currents, related to the stratification, which was itself enhanced by the fact that the wind had pushed the superficial light-water pool offshore while thinning it down. Closer to the coast the succession of downwards and upwards motions had increased the turbulent mixing by reducing the stratification, which explains the lower speed of the surface current. During the entire period of northwest wind, the former plume was thus carried offshore by the wind at a speed of about $30 \mathrm{~cm} \mathrm{~s}^{-1}$ [Fig. 10(c)]. As will be seen in greater detail in the simulation of 26 September, the drift of this freshwater pool has much in common with the alongshore intrusion of the salinity front in the absence of wind. On 14 September starting at 06.00 hours, the wind rotated to a southwest wind while growing weaker. This wind direction favoured an eastwards flow of water discharged by the river mouth, enabling the plume to penetrate into the Gulf of Fos [Fig. 10(d)]. The effect of this new configuration was to isolate the waters of the former plume, located to the southwest of the river mouth, which, due to a significant weakening of the wind, were subjected to strong inertial oscillations like the surrounding ocean waters. A clockwise rotation of the current, directed shorewards and then eastwards at the end of the simulation, could thus be observed in the diluted waters of the former plume [Fig. 5(d)]. The effect of these inertial oscillations was to accelerate the dilution of the waters of the former plume by lateral advection. The plume as observed from space thus consisted of highly turbid, recently discharged freshwater in its eastern part, while its more diffuse west part consisted of waters discharged earlier whose dynamics were no longer forced by the river mouth but were rather dominated by inertial oscillations.

\subsection{The situation on 26 September 1993}

4.3.1. Examination of the satellite image. The reflectances determined from the AVHRR data on 26 September 1993 at 16.00 hours are shown in Fig. 5(e). The shape of the plumes of the Petit and Grand Rhones is compatible with observations of Demarcq and Wald (1984) in the event of a northwest wind, although the eastwards deviation of the two plumes in front of the river mouth is particularly prominent here (see Section 5). The turbidity maximum is located about $5 \mathrm{~km}$ to the southeast of the river mouth. In front of the mouth, the plume incites an anticyclonic eddy and is then directed towards the southwest. The sizeable extension of the plume is due to increases in the Rhone River discharge (more than $5000 \mathrm{~m}^{3} \mathrm{~s}^{-1}$ ) related to the heavy rainfall of the preceding days. It should be emphasized that of the three September maxima, the flood of 26 September is by far the greatest. Moreover, the first autumn floods to occur after the low discharge aestival period are propitious to the cleansing of the soil and thus lead to the seaward transport of large quantities of particulate matter, which explains the high concentrations observed.

4.3.2. Meteorological conditions. The meteorological conditions in the 4 days preceding the image [Fig. 2(c)] were characterized by a southeast wind favouring downwelling during the first 2 days, followed by a northwest wind favouring upwelling. 
4.3.3. Comparison of the satellite image with the model results. The concentrations of suspended matter obtained at the end of the simulation [Fig. 5(f)] should be compared with the reflectances in Fig. 5(e). The simulated shape of the plume is commensurate with the radiometer observation. In both cases the eastern side of the plume, where the concentration gradients are more intense, is clearly delimited, while the western edge is more diffuse. As was the case in the 14 September 1993 simulation, the concentration maximum is not located at the river mouth but rather a few kilometers offshore, a fact which is not reproduced by the model results.

4.3.4. The simulation of 26 September 1993 . The period of southeast wind with which the simulation began led the plume to expand alongshore [Fig. 11(a)], thus displaying similarities to the solutions previously obtained with such forcings [Figs 6(a) and 10(a)]. Here, however, the river discharge was very high and the weak wind did not influence the
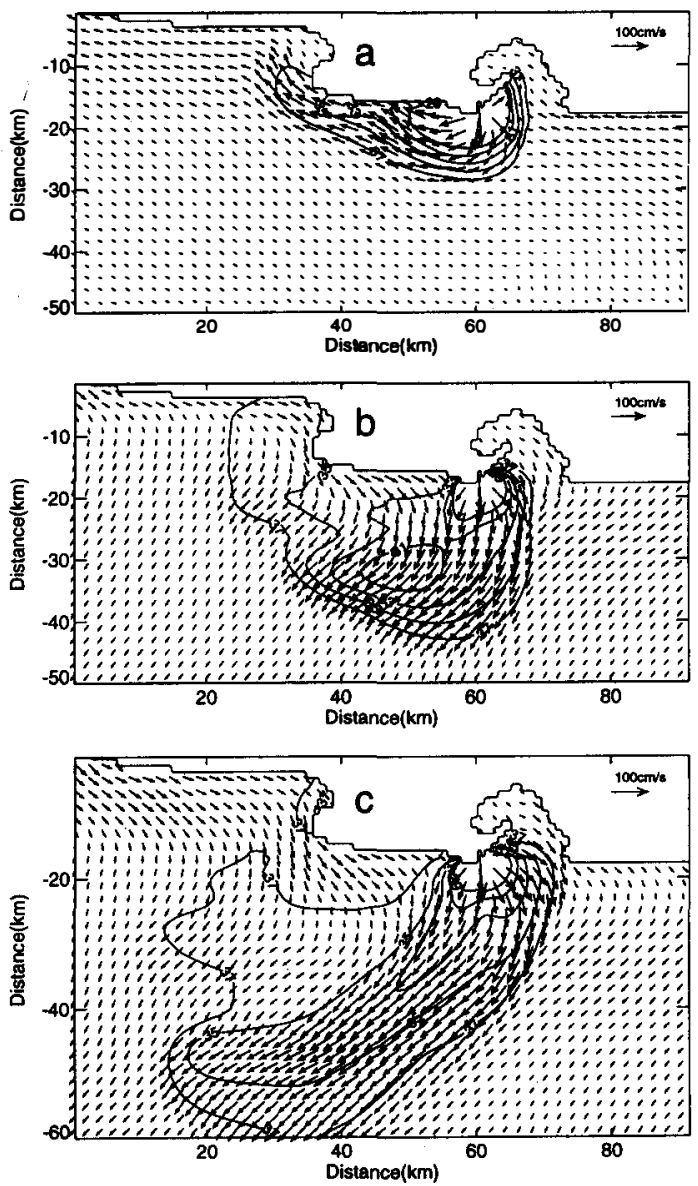

Fig. 11. Computed surface salinities and currents corresponding to different times: (a) 24 September 1993, 12.00 hours, (b) 25 September 1993, 08.00 hours, (c) 26 September 1993, 02.00 hours. Interval between salinity isocontours: 2 psu, contours lower than 29 psu are not plotted for clarity. 

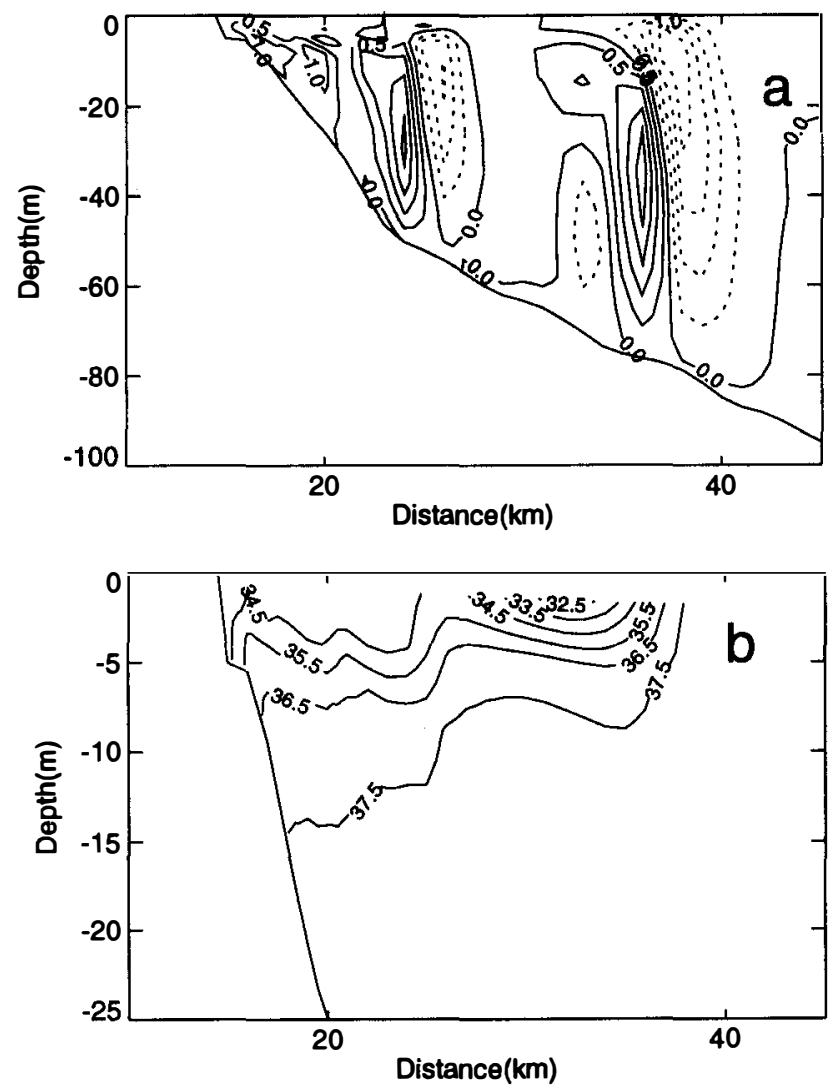

Fig. 12. North-south vertical sections of (a) vertical velocity (in $\mathrm{m} \mathrm{hour}^{-1}$ ), (b) salinity, taken $20 \mathrm{~km}$ westward of the river mouth and corresponding to 25 September 1993 at 08.00 hours.

plume to as great an extent. In fact, the shape of the plume brought to mind the characteristics of Chao and Boicourt's numerical simulations without wind (1986) in which an anticyclonic bulge developed in front of the river mouth, whereas this had been absent from the previous simulations due to the intense southeast wind. The rotation to a northwest wind is associated with the seaward detachment of the plume, as has already been discussed in the previous two simulations and will thus not be detailed here. However, this case may be distinguished from the previous cases by the existence of a lightwater pool, which may be observed at the 31-psu isohaline of Fig. 11(b), distinctly detached from the rematerialized plume at the river mouth. This detachment was encouraged by the pronounced vertical stratification-indeed, the plume which formed at the start of the simulation, thin and very low in salt content due to the weakness of the southeast wind, was then quickly carried offshore by the northwest wind due to the low degree of interfacial mixing. The movement of this freshwater pool induced a quasi-twodimensional circulation in the leading front, similar to the coastal bore intrusion described by Chao and Boicourt (1986), with a downwelling at the front end tending to thicken the nose of the bore, and a deeper upwelling at the rear end (Fig. 12). The horizontal circulation pattern, which is not shown here, revealed the existence beneath the fresh- 
water pool of an undercurrent with a maximal velocity of $15 \mathrm{~cm} \mathrm{~s}^{-1}$. A second freshwater pool may also be seen in Figs 11(b) and 12(b), farther to the north and consisting of the water accumulated against the coast during the southeast wind event, the dynamics of which as far as the front is concerned were similar to the first pool [Fig. 12(a)].

The velocity of front advancement was calculated over the first few hours of northwest wind, during which the salinity front was still quite pronounced. The front advanced $8 \mathrm{~km}$ in 5 hours. This velocity was compared to that measured by Forget et al. (1990) with a VHF radar during a northwest wind episode, the intensity of which was very close to the current case. The front observed by the radar had advanced $20 \mathrm{~km}$ towards the south in 12 hours. Although this advancement occurred closer to the river mouth than in the present study, due to the much lower river discharge, the velocities of front advancement are analogous. The current speeds inside and in front of the plume were also compared. Here our results are also similar, since inside the plume the currents measured vary from 40 to $80 \mathrm{~cm} \mathrm{~s}^{-1}$, while in front of the plume the velocities were of the order of $10-20 \mathrm{~cm} \mathrm{~s}^{-1}$. In the case of Fig. 11(b), the higher velocities inside the plume are about $75 \mathrm{~cm} \mathrm{~s}^{-1}$, while outside of the plume the current velocity is of the order of $15-20-\mathrm{cm} \mathrm{s}^{-1}$.

The wind action continued and the plume detached completely from the coast. This wind configuration was interesting, since unlike the previous cases, the northwest wind continued until the moment of observation, enabling the plume to stretch offshore [Fig. 11(c)]. At the plume tip, which was oriented east-west, the waters which had been detached the day before under the effect of the rotation of the wind could be found. At the coast the persistent upwelling had entirely renewed the water column and the freshwater pool which had been carried away from the coast was still visible farther to the south. The plume still clearly seemed, within the deformation radius, to be under the influence of the strong coastal current, which encouraged its eastwards expansion and prevented development towards the west, giving it this characteristic shape of a comma which has also been observed from the satellite.

\section{DISCUSSION}

In the previous section, it has been observed, through three simulations, that the Rhone River plume is highly sensitive to wind. However, two types of plume appeared in the cases described - on the one hand the plumes associated with a north wind, detached from the coast and globally oriented towards the southwest, [Figs 6(c), 10(c) and 11(c)] and on the other hand the plumes associated with a southeast wind, thin and hugging the coastline to the west of the river mouth [Figs 6(a) and 11(a)]. One would be tempted to ask if these two types of plume are generally representative of the Rhone River plume's dynamics. First of all, as has been mentioned in Section 2, the two wind regimes associated with these two types of plume are predominant in the climate of the Gulf of Lions. Moreover, Demarcq and Wald (1984) have conducted a statistical study of the shape of the Rhone River plume as a function of the different wind sectors, which highlighted the two characteristic shapes mentioned above (see Fig. 13, following Demarcq and Wald, 1984). This figure is also interesting in that it validates the cases of southeast wind which are not shown in the satellite images of Fig. 5. Moreover, it should be noted that such images are rare, as these weather conditions are often accompanied by cloud cover which makes space observation impossible.

Another characteristic of the simulations described is the considerable influence of 

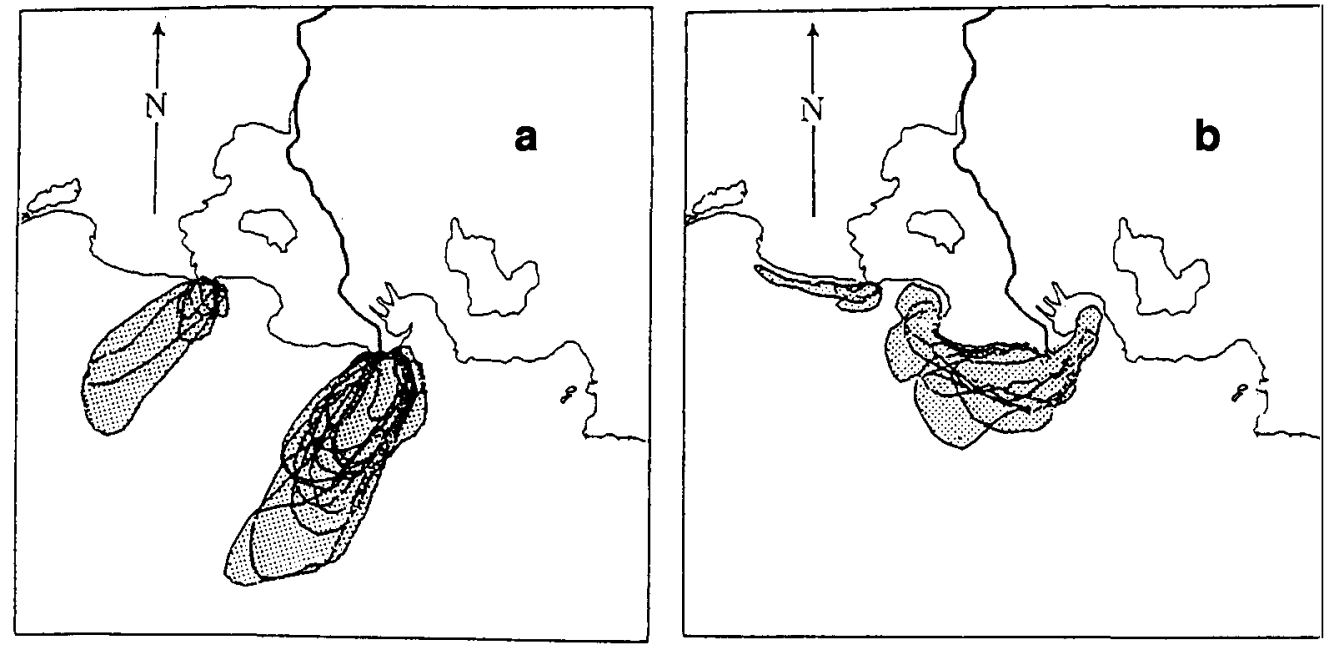

Fig. 13. Re-drawn from Demarcq and Wald (1984). Superposition of Rhone plume contours on different dates for wind blowing from (a) northnorthwest, (b) east-southeast.

wind-induced coastal currents on the shape of the plume. The width and strength of these currents, linked to the internal deformation radius, are naturally related to the ocean stratification which varies as a function of the season. From this point of view, the simulations described in this article, all of which correspond to the month of September, cannot bring to the fore the seasonal variability of the plume. We thus conducted a study of plume sensitivity to the stratification, on the basis of simulations forced by a constant freshwater discharge, wind speed and wind direction. Figure 14(a) shows that during the summer the presence of the eastward coastal current, reinforced by the contribution of the baroclinic mode, deviates the plume eastwards in the first $10 \mathrm{~km}$ from the coast, which gives it the curved shape observed on the image of 26 September 1993, for example [Fig. $5(\mathrm{e})]$. In the case of the winter time, the weakness of the coastal current gives a more rectilinear appearance to the plume, which corresponds quite well to the observations made by Demarcq and Wald (1984) (Fig. 13). In the case of the southeast wind, the weakening of the westward coastal current in winter encourages the penetration of the river waters into the Gulf of Fos to the east of the river mouth [Fig. 14(b)].

\section{CONCLUSION}

The modelling of the Rhone River plume in real situations has made it possible to analyse satellite observations in which the structures are often complex and difficult to interpret through a mere examination of the meteorological and hydrological conditions. We were able to establish that the plume is subjected to two determining forcings: the wind and the surrounding coastal circulation. The wind forcing determines the overall orientation of the plume while the coastal current induced by winds favouring either upwelling or downwelling is often dominant inside the internal deformation radius, i.e. in the area near to the river mouth, governing for example, the eastwards extension of the plume or its penetration into the Gulf of Fos. The three experiments performed show the response 

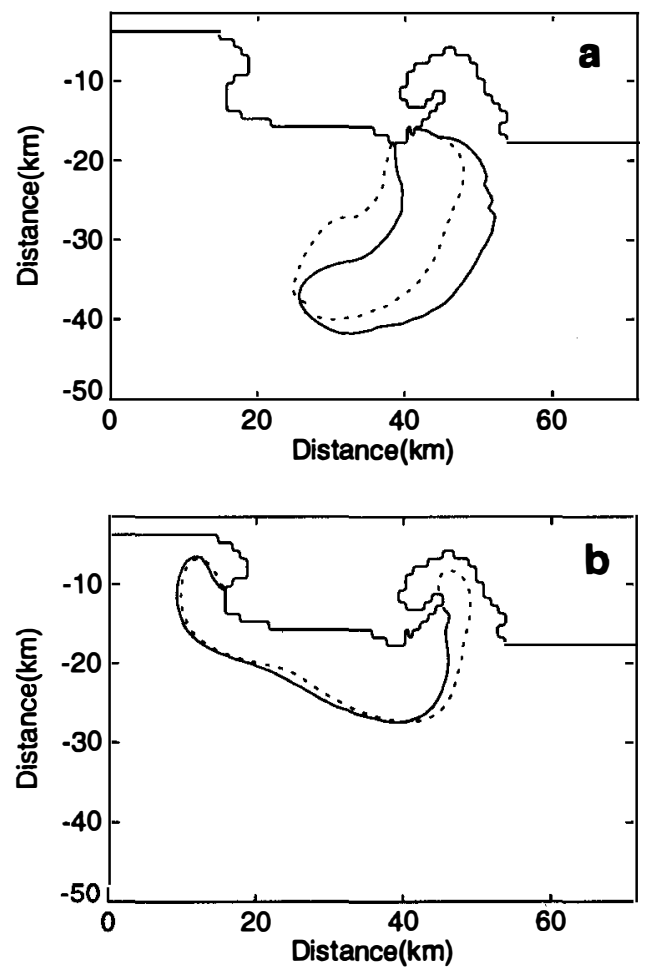

Fig. 14. Plume contours corresponding to a Rhone discharge of $1500 \mathrm{~m}^{3} \mathrm{~s}^{-1}$ and (a) a northnorthwest wind of $10 \mathrm{~m} \mathrm{~s}^{-1}$, (b) a southeast wind of $5 \mathrm{~m} \mathrm{~s}^{-1}$. Initial stratification of oceanic waters typical of-summer conditions: solid line, winter mixed conditions: dotted line.

time of the plume to changes in the wind orientation. The constraint of the plume by the coastal current is more difficult to predict as the response time of the coastal current to the wind is highly variable and depends on the stratification. We were able to show its sensitivity to the succession of wind events and to the bathymetry.

With each significant wind rotation the plume changed direction at the river mouth, while the freshwater pools formed earlier and thus isolated from the new plume were pushed by the wind and in many cases subjected to inertial oscillations. The inclusion of a buoyancy effect on the turbulence intensity plays an important role in the acceleration of these superficial freshwaters by the wind and in the time scales of their dilution.

While the comparison of model results with observations is convenient from a qualitative point of view, it should nevertheless be noted that the calculated gradients of suspended matter concentration were not always commensurate with the corresponding satellite data. This could in part be attributed to the overly simplistic representation of settling velocity in the simulations. Moreover, a discrepancy was noted in the location of the concentration maxima, which were found at the river mouth in the numerical simulations, but were sometimes observed a few kilometers offshore in the satellite image. The fact that the resuspension of the fine-grained particles of the sediment layer in the Rhone River prodelta was not included probably accounts for this failure in the model. In the years to come, one challenge facing the models will be to trace the fate of the matter 
brought by the rivers into the oceans. A particularly delicate point will be in the complexity of the processes affecting these particles, not only physical processes such as flocculation, but also biological processes which are of special importance in river waters due to the presence of nutrients, generating large particles which interact considerably with the terrigenous matter. These complex problems are of course beyond the scope of this article, one objective of which is to help validate a three-dimensional model of river plumes. It should nevertheless not be forgotten that the model/image comparison is quite obviously limited by the fact that these processes have been omitted.

In light of the considerable effect of the coastal current on the plume and the difficulty of predicting this current due to its sensitivity to the initial conditions, a significant improvement in model performance could be attained by assimilating measurements of this current. Surface current measurements in the Rhone River plume have recently been obtained by means of VHF radars (Arnoux et al., 1995). The comparison of these measurements with the model results ought to enable an extensive validation of the modelling.

Acknowledgements - This study was supported by the European Community MAS3-CT96-0049 research programme and the French Programme National d'Océanologie Côtière (National Program of Coastal Oceanography). The authors thank H. Massé who coordinates the research of the PNOC group in the Gulf of Lions and S. Prieur for technical assistance.

\section{REFERENCES}

Arakawa, A. and Suarez, M. J. (1983) Vertical differencing of the primitive equations in sigma coordinates. Monthly Weather Review 111, 34-45.

Arnoux, S., Baeckeroot, A., Baghdadi, N., Broche, P., Devenon, J. L., Forget, P., Gaggelli, J., de Maistre, J. C., Ouillon, S., Rey, V. and Rougier, G. (1995) Field campaign off the Rhone River mouth. In Proceedings of the Second International Conference on the Mediterranean Coastal Environment, MEDCOAST 95, ed. E. Özhan, pp. 869-882. MEDCOAST Secretariat, Middle East Technical University, Ankara, Turkey.

Asselin, R. (1972) Frequency filters for time integrations. Monthly Weather Review 100, 487-490.

Balopoulos, E. Th., Collins, M. B. and James, A. E. (1986) Satellite images and their use in the numerical modelling of coastal processes. International Journal of Remote Sensing 7, 905-919.

Blumberg, A. F. and Mellor, G. L. (1987) A description of a three-dimensional coastal circulation model. In Three Dimensional Coastal Ocean Models, Coastal and Estuarine Sciences Vol 4, ed. N. S. Heaps, pp. 1-16. American Geophysical Union, Washington, D.C.

Bougeault, P. and Lacarrère, P. (1989) Parameterization of orography-induced turbulence in a meso-beta scale model. Monthly Weather Review 117, 1872-1890.

Brun-Cottan, J. C. and Li, Z. H. (1991) Impulsive sediment resuspension in the Gulf of Lions. In Water Pollution Research Report 28, Eros 2000, eds, J. M. Martin and H. Barth, pp. 51-62. Commission of the European Communities, Brussels.

Caniaux, G., Roquet, H. and Planton, S. (1993) A 3-D mesoscale simulation of the ocean using data from the ATHENA 88 field experiment. Journal of Marine Systems 4, 197-216.

Chao, S.-Y. and Boicourt, W. C. (1986) Onset of estuarine plumes. Journal of Physical Oceanography 16, 21372149.

Chao, S.-Y. (1987) Wind-driven motion near inner shelf fronts. Journal of Geophysical Research 92, 3849-3860.

Chao, S.-Y. (1988) River forced estuarine plumes. Journal of Physical Oceanography 18, 2137-2149.

Courp, T. and Monaco, A. (1990) Sediment dispersal and accumulation on the continental margin of the Gulf of Lions: sedimentary budget. Continental Shelf Research 10, 1063-1087.

Demarcq, H. and Wald, L. (1984). La dynamique superficielle du panache du Rhône d'après l'imagerie infrarouge satellitaire. Oceanologica Acta 7(2), 159-162.

Demarcq, H. (1985) Applications de la télédetection infrarouge et visible en océanographie. Ph.D. Thesis, University of Aix-Marseille II, Marseille. 
Durrieu de Madron, X., Nyffeler, F. and Godet, C. H. (1990) Hydrographic structure and nepheloid spatial distribution in the Gulf of Lions continental margin. Continental Shelf Research 10, 915-929.

Forget, P., Devenon, J. L., De Maistre, J. C., Broche, P. and Leveau, M. (1990) VHF Remote sensing for mapping river plume circulation. Geophysical Research Letters 17(8), 1097-1100.

Garvine, R. W. (1987) Estuarine plumes and fronts in shelf waters: a layer model. Journal of Physical Oceanography 17, 1878-1896.

Gaspar, P., Gregoris, Y. and Lefevre, J. M. (1990) A simple eddy kinetic energy model for simulations of the oceanic vertical mixing: tests at station Papa and long-term upper ocean study site. Journal of Geophysical Research 95, 179-193.

Got, H. and Aloisi, J. C. (1990) The Holocene sedimentation on the Gulf of Lions margin: a quantitative approach. Continental Shelf Research 10, 841-855.

Haltiner, G. J. and Williams, R. T. (1980) Numerical Prediction and Dynamic Meteorology. John Wiley \& Sons, New York, $477 \mathrm{pp}$.

Hsu, S. A. (1986) Correction of land-based wind data for offshore applications: a further evaluation -Journal of Physical Oceanography 16, 390-394.

Johns, B., Rao, G. S., Dube, S. K. and Sinha, P. C. (1991) An application of a wind-driven coastal upwelling model in the western Bay of Bengal. Continental ShelfResearch 11, 295-319.

Johns, B., Marsaleix, P., Estournel, C. and Véhil, R. (1992) On the wind-driven coastal upwelling in the Gulf of Lions. Journal of Marine Systems 3, 309-320.

Kondrachoff, V., Estournel, C., Marsaleix, P., Vehil, R. and Zbinden, R. M. (1994) Detection of the Rhone River plume using NOAA-AVHRR data. Comparison with hydrodynamic modeling results. In Oceanic Remote Sensing and Sea Ice Monitoring, SPIE proceedings series 2319, pp. 73-84. Society of Photo-Optical Instrumentation Engineers, Washington.

Mellor, G. L. and Yamada, T. (1982) Development of a turbulence closure model for geophysical fluid problems. Review of Geophysics and Space Physics 20, 851-875.

Millot, C. (1976) Specific features of the sea-shore circulation near Cap Leucate. Mémoires Société Royale des Sciences de Liège, 6ème série, tome X, 227-245.

Millot, C. and Crépon, M. (1981) Inertial oscillations on the continental shelf of the Gulf of Lions-observations and theory. Journal of Physical Oceanography 11, 639-657.

Millot, C. and Wald, L. (1981) Upwelling in the Gulf of Lions. In Coastal Upwelling, Coastal and Estuarine Sciences vol 1, ed. F. A. Francis, pp. 160-166. American Geophysical Union, Washington, D.C.

Millot, C. (1990) The Gulf of Lions' hydrodynamics. Continental Shelf Research 10, 885-894.

Nihoul, J. C. J. (1984) Contribution of remote sensing to modelling. In Remote Sensing of Shelf Sea Hydrodynamics-Proceedings of the 15th International Liege Colloquium on Ocean Hydrodynamics, ed. J. C. J. Nihoul, editor. Elsevier Oceanography Series 38, pp. 25-36.

O'Donnell, J. (1990) The formation and fate of a river plume: a numerical model. Journal of Physical Oceanography 20, 551-569.

Oey, L.-Y. and Mellor, G. L. (1993) Subtidal variability of estuarine outflow, plume and coastal current: a model study. Journal of Physical Oceanography 23, 164-171.

Pinazo, C., Marsaleix, P., Millet, B., Estournel, C. and Véhil, R. (1996) Coupled modelling of physical and biological processes in the Gulf of Lions (northwestern Mediterranean): spatial and temporal variability. Journal of Marine Systems 7, 161-191.

Ruddick, K. G., Deleersnijder, E., Luyten, P. J. and Ozer, J.(1995) Haline stratification in the Rhine-Meuse freshwater plume: a three-dimensional model sensitivity analysis. Continental Shelf Research 15, 15971630.

Skibitzke, H. E. (1976) Remote sensingfor water resources. In Remote Sensing Environment, eds J. Lintz and D. S. Simonett, pp. 572-592. Addison-Wesley Publishing Company, Reading, Massachusetts.

Stumpf, R. P. (1987) Application of AVHRR satellite data to the study of sediment and chlorophyll in turbid coastal water. NOAA technical memorandum NESDIS AISC 7, Washington, D.C.

Tanré, D., Deroo, C., Duhaut, P., Herman, M., Morcrette, J. J., Perbos, J. and Deschamps, P. Y. (1986) Description of a computer code to simulate the satellite signal in the solar spectrum: the $5 \mathrm{~S}$ code. International Journal of Remote Sensing 11, 659-668.

Weaver, A. J. and Hsieh, W. W. (1987) The influence of buoyancy flux from estuaries on continental shelf circulation. Journal of Physical Oceanography 17, 2127-2140.

Wu, J. (1980) Wind-stress coefficients over sea surface near neutral conditions-a revisit. Journal of Physical Oceanography 10, 727-740. 